\title{
Fashion Your New Library from Old
}

by William R. Burgin

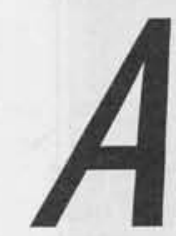

lthough library planners often initially consider new construction when undertaking a building project, it is important to explore renovation, addition, and adaptive re-use of existing facilities as equally viable options. Careful evaluation of an existing building's potential for addition or renovation, or of another building's potential for a second life through adaptive re-use, can yield fruitful results. Statistics reported recently by Library Journal suggest a trend toward addition and renovation over new construction, indicating that library planners see definite advantages to improving library facilities through the use of existing buildings. ${ }^{1}$

Renovation, addition, and adaptive re-use offer many incentives in preference to new construction. Under the right circumstances, a library has the opportunity to gain any or all of the following advantages:

- Money can be saved. The general rule of thumb when considering an extensive renovation is that the structure and building shell (outer wall, floors and roof decking) are worth approximately $30 \%$ of a building's total cost. Thus, if a new building is compared to an existing building of equal size, $30 \%$ of the cost is in place. ${ }^{2}$ In cases of a change of site (adaptive re-use), the purchase of property may require an expenditure in excess of this amount. Renovating your existing library building certainly would start with this cost advantage. If a purchase of property is a consideration, the sale of the existing library building may be an option to preserve the $30 \%$ shell cost advantage.

In addition, many existing buildings still have some life left in their infrastructures (i.e., plumbing, mechanical, and electrical systems). If you're fortunate, the existing sewer main will be reusable, the air distribution ducts can be utilized, and portions of the main electrical distribution duct will be recyclable.

Advantages from these savings may enable you to build a larger library or to begin your project years earlier than waiting for the funding for a new facility would require.

If the targeted effort produces a project as "good as new," it is appropriate to compare directly the cost of a renovation/ addition or adaptive re-use with a new building. Don't let a renovation/adaptive reuse project die because the cost projections appear modest. A savings of only $\$ 10.00 /$ square foot over new for a 10,000 square foot library results in a savings of $\$ 100,000$. Even allowing for the unexpected contingencies typically found when renovating ( $5 \%$ of the project cost), the savings easily could be realized at $\$ 50,000$. Certainly this is enough money to fill several ranges of shelving with books.

- A historical or architecturally significant building may be given a second life. Frequently communities have historical buildings that can produce a final library building more richly detailed than a comparably priced new building. Most older buildings were built when materials were cheap and labor costs were low enough to afford the installation of architectural amenities (raised paneling, wood casings, wood crown mouldings, solid doors, etc.). With a resourceful architectural design, it may be possible to salvage and complement such architectural details. The result could be a richly detailed library building. Even at a premium cost, these opportunities merit consideration. Certainly the politics of preservation may provide additional funding for such an endeavor. The marriage of a library (a community asset set in tradition) with an architecturally significant structure can make a perfect match.

- A renovation/addition project could preserve the traditional location of the community library. Libraries frequently are situated in central locations within communities. Over time, the library may actually form the hub of a community. With the proper addition and renovation, this traditional center of a community may remain intact for generations. It also is common for the renovation of a significant municipal building (and certainly a library is one of the most significant of community facilities) to begin a city or community revitalization.

- An adaptive re-use may speed the opportunity to relocate your library in a more desirable location, out of a deteriorating neighborhood, or into an area closer to the library's user population. New projects are time consuming to assemble because they include multiple layers of steps and approvals. Beginning with property acquisition, the new project moves slowly through years of political and governmental budget maneuvering. Adaptive re-use, renovations, or renovations and additions focus planning on a singular effort.

Assuming that the building being considered is large enough, or can be expanded to house the library's space requirements, begin review of your prospective building (including your existing library building in case a renovation and/ 
or addition may be appropriate) for at least the elements listed below. By following this list of building criteria and evaluation, you may uncover a jewel of a building solution.

\section{Structure}

Libraries do have demanding structural requirements. The live loads (those loads applied to the structure by the occupant) are 125 pounds per square foot (psf) for stacks, 80 psf for public corridors, and as much as 250 psf plus for file and film material storage. This compares to typical business facility live loads of 50 psf for the office spaces and 100 psf for public lobbies. $^{3}$

Since the economics of construction dictate that a structure be planned to carry just the loads anticipated and no more, one must assume that unless the renovation is to a building type with matching load criteria, the structure will need strengthening. This is not impossible and, depending upon the type of structure, will pose different levels of difficulty. Obviously the greater the difficulty, the costlier the modifications.

The skeletal arrangement of a building's framing is key to a building's present and future flexibility. Flexibility always is tested during renovations and adaptive re-use designs. It is the key to achieving your future library program requirements. The skeletal framing (a structural arrangement composed of columns, both perimeter and interior, supporting girders, and beams supporting a floor deck) allows the library program criteria to be easily planned within the grid formed by the structural columns. In a building with a skeletal frame, an existing wall which must be removed to accommodate the library plan will be non-structural and fairly inexpensive to demolish. If the adaptive building size is less than required by the program, exterior non-load-bearing walls also can be removed easily to allow for the necessary building addition, while creating an adequately large, open connection that will produce good visual control within any given space plan.

Look for buildings with the following structural types. They are listed in the order of probable success.

\section{Single story buildings with slab on grade floor structures with skeletal framing (most probable structural match)}

The slab floors more than likely will be able to carry all library loading conditions. Concrete slabs are generally poured four inches thick or thicker. This is the thickness required to prevent cracking and to allow working the concrete over inevitable variations in the slab's substrate. These floors are capable of carrying library stack live loads without modifications.

\section{Multistory buildings with skeletal framing:}

Multistory buildings potentially are not as successful as single story buildings. Because of the economics of construction mentioned, columns and beams forming the skeletal frame must be analyzed closely and probably modified to meet a library's added structural needs. The type of materials from which these frames are made is an important factor in determining the building's flexibility for adaptive re-use.

Framing is more easily analyzed and adapted for carrying an increased load if it is steel. In all cases, engineers easily can measure spans of beams and heights of columns. This is true no matter what framing materials were used. Engineers, however, also must develop framing member section characteristics to complete a structural analysis. This is managed easily if the structure is of steel rather than any other build material. Concrete structures also are worthy of analysis because of their superior fire resistant nature and a reasonable ability to accept modifications to enhance structural capacities. One major drawback in analyzing concrete struc- ture, however, is the difficulty in determining the sectional characteristics of concrete beams or columns. This is because the structural characteristics of concrete are created in partnership with reinforcing steel hidden within the concrete. If the original building plans are available and contain descriptions of the steel reinforcing, the analysis can be completed fairly easily. If drawings do not exist, conservative and cautious assumptions or destructive analysis must be undertaken. Either method adds cost to the early building analysis phase of the process.

\section{Multistory buildings with exterior bearing walls and interior skeletal framing}

A reasonable compromise would be adapting or renovating a multistory building with exterior bearing walls and interior columns, girders and beam, and floor decking. It's particularly worth consideration if the exterior dimensions of the building exceed the library program's overall space requirements or if the exterior building dimensions meet distinct portions of the building program. In the latter case, the renovated structure can house those distinct portions, and an addition can be added to address the balance of the library's program needs.

\section{Exterior and interior bearing walls (Most improbable structural match)}

It would be very difficult to reuse a building whose structure consists of both exterior and interior bearing walls. These buildings offer very little flexibility, the basic building block in library planning. Consider this example of the difficulties ahead: to create a large space for stacks (in such a way as to offer visual control), bearing walls that form smaller spaces must be removed. In order to accomplish this, the walls that support the structure above must be replaced with beams and columns. This process is complex and requires expenditures for both demolition and installation of framing required to remove the structural wall. The support for the new columns also must begin at ground level. This means new footings. In cases where this type of improvement occurs on upper floors, the columns must extend to the footing through the lower floors. In addition, the new structure must be in place before the bearing walls are removed. Though the results may be acceptable, this expensive process will generate no additional building square footage. Finally, if any of the building's infrastructure (i.e. conduit, ductwork, plumbing, etc.) is in the way of the new column and beam system, it too may have to be torn out and reinstalled, adding even more expense to the effort.

\section{Hazardous Materials - Watch Out!!}

Hazardous materials can jeopardize the success of a renovation or adaptive re-use project. These hazards typically come from asbestos, lead paint, and lead content in water piping (from lead-base solders used to make joints in copper piping), and ground water contamination. A walk-through of a prospective building can be a first indicator of potential hazardous material problems.

Many states, including North Carolina, require a hazardous material survey prior to beginning demolition for renovation of a building. ${ }^{4}$ This is not particularly expensive and is performed by companies specializing in material testing. This survey should be provided by the building owner as a condition of a purchase option. (The results are valuable to the property owner for subsequent sales efforts even if the library does not purchase the property.) Reports from independent testing professionals carry such significant liabilities that the chance of a company fabricating favorable results for an owner to entice 
a purchase is unlikely. Certainly, the results can be verified later, just prior to a final purchase, if the library feels more comfortable retaining services for these tests directly.

Asbestos can be found in any number of building materials, particularly in buildings predating 1970 . The worst forms of asbestos are found in materials that have become dry and powdery. These friable materials require intensely controlled abatement. Procedures must be designed and followed to protect workers and building occupants from these carcinogenic asbestos fibers. In addition, only a small number of locations exist that allow disposal of this friable debris. During a building's review, look for this type of asbestos in materials insulating HVAC hot and cold water piping (particularly around valves and joints), domestic water piping (particularly around valves), ductwork (outer layers of insulation), boilers (both as

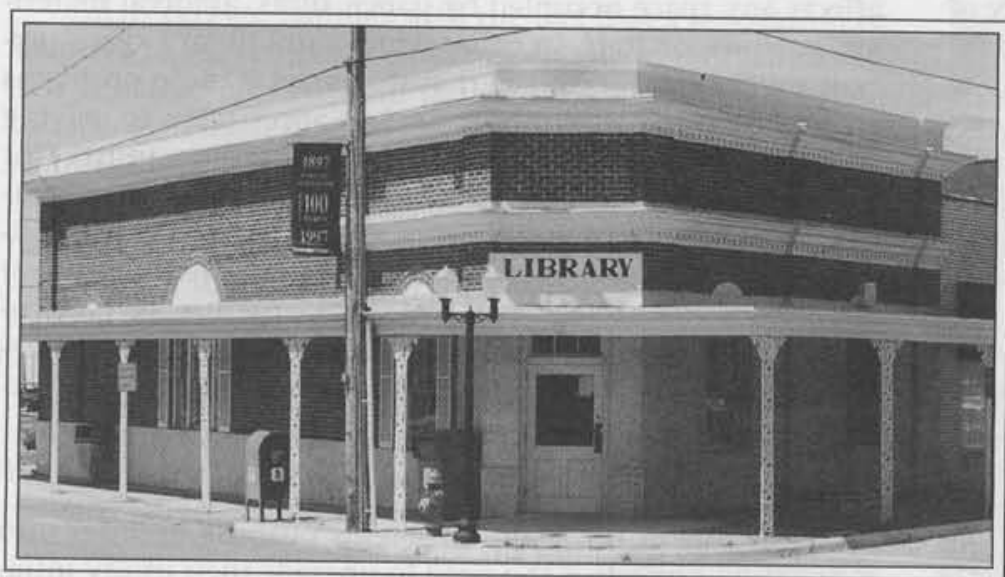

Two new branches of the Sheppard Memorial Library in Greenville are classic examples of adaptive reuse of architecturally interesting buldings. Winterville's 1,455 sq.ft. C.D. Langston/R. E. Boyd Library is a converted bank building. Bethel's 2,000 sq. ft. Margaret Little Blount Library is a converted train station. Architect: Hite-MSM Architects (Greenville.) Photo: Willie Nelms.

exterior insulation and interior fire box liners), and in acoustical plaster (mainly found in ceiling plaster). These materials are predominately white, $1 / 2$ inch to 1 inch thick, and caulky. These materials are very, very costly to remove.

Other asbestos materials frequently found in older structures include asbestos floor tile (usually 9'x9' tiles sizes), vinyl sheet flooring, mastics used to glue flooring materials to the subfloor (black in color), acoustical

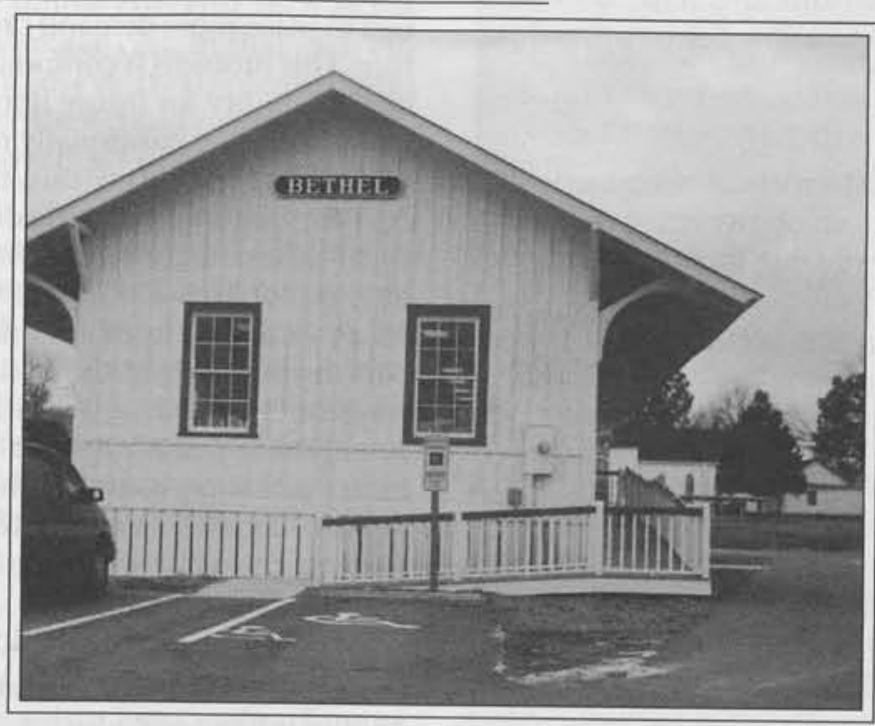
ceiling tile (usually 12 "x 12 " tiles sizes), and hard board paneling (used both for interior and exterior applications). These products contain asbestos in an encapsulated form. If they are removed carefully by qualified personnel, this abatement can be expected to cost less than friable abatement. Even disposal is less tricky, since many local landfills still handle these non-friable, asbestos-containing materials.

Another major hazardous material is lead-based paint. Lead-based paints commonly were used in quality construction projects prior to the 1960 s. This material can be handled several different ways. The best method is to remove the lead- based materials totally. Methods for accomplishing this removal include dissolving the lead chemically; tearing off the top, thin layer of wall surface; or blasting the surface with abrasive material until the paint surface is gone. Since children comprise a major segment of a library's patrons and are a group most susceptible to lead dangers, it seems prudent to consider total removal in all circumstances.

Other acceptable methods of dealing the lead-based paint include covering the walls with a new material, encapsulating the lead behind the new material. An example of this is to apply a layer of gypsum board over any wall finished with lead-based paint. Additionally, the hazardous material industry has many coating products which will encapsulate the lead and provide a surface that accepts a new enamel or latex-based paint or vinyl finish. The disadvantage of these encapsulating options occurs in the future when these surfaces must be demolished. Lead abatement during a late renovation phase could create several limitations for the library if renovation takes place while the library is in operation. Even a very small renovation could close down a significant portion of library services.

Lead in the water system occurs because of leadbased solder used in pipe joints, a common plumbing practice used in quality construction projects prior to the 1960 s. The best solution for water system lead is to remove all the old domestic water copper piping, as well as water coolers, within the building.

Ground water contamination may be a problem if an old oil tank is existing (or existed at any time) on the site. This hazard is not peculiar to renovations. Obviously this hazard is probable on a site with previous construction history where oil was used as a fuel, or worse yet, where oil was distributed. You should request from the owner any history of underground storage tanks and have a soil sample taken to determine if contamination has taken place. Also look around the site for the fill caps that were used to fill these underground tanks. Soil contamination testing can be handled by the same testing professionals mentioned for asbestos and lead paints. Depending upon the extent and length of time the leakage has occurred, this type of contamination can prove very expensive.

\section{Life safety}

An analysis of how a potential library might respond to life safety issues is the next important issue to resolve. As a general rule, the combustibility of materials used in the construction of a building, the type and quality of the building's exitway system, and the size of the building are characteristics to review.

Concrete will prove a better material to resist fire than steel. This is because steel loses its strength quickly in high temperatures, a factor that reduces escape time before a building's collapse. Steel, in turn, will prove a better material in terms of fire resistance than wood. Wood is a contributor to fire and will quickly be consumed and collapse. Because of this, the codes allow larger areas to be built (with less demand- 
ing restrictions) for buildings constructed of concrete than buildings constructed of steel or wood.

As codes evolve, each writing typically becomes more and more conservative. Present codes, therefore, closely address the number and quality of exits and are probably more demanding than they were when an older building was constructed. It is not uncommon in older buildings to find a single stairway serving a multi-floored building. If your prospective building is to be born anew, plan on providing for at least two exits. Even if two exits from every floor are not required by the code, it certainly is good practice. Libraries contain ranges for fuel (books) for a fire and frequently are filled with children and adults unfamiliar with escape routes. Obviously, if two buildings are contenders for purchase and one has two good exits, it deserves higher consideration.

The other factor when examining exits is the quality of the exit's construction. In order to make the exits more fireresistant, masonry walls and steel or concrete treads and risers should be used. Another factor to consider is the remoteness of the stairs from each other. Ideally, the stairs are located at the far extremes of the building, with the library's functions located between these exits. If one stair currently exists, it will more likely be located in the center area of the building plan. Though this has the advantage of providing centralized vertical movement, it comes at a potentially high price to life safety performance. With this in mind, plan to spend money to move stairs if it is needed.

Related to life safety (but part of the building's electrical infrastructure) is a modern electronic fire alarm system. A good choice here can bolster the life safety performance of any older building. These systems include pull stations (for manual triggering of alarms), smoke detection, heat detection, automated telephone notification, and visual and audio alarms. These systems should be designed to comply with NFPA standards and will in effect create an early warning system to allow safe evacuation of patrons and staff. They also will notify emergency personnel to allow for improved response time.

\section{Siting}

Siting issues are generally the same with new and existing buildings; in the case of renovations, however, you have a distinct advantage. You are able to observe most of the important site criteria such as:

- How storm water is routed on site. Is the water directed away from the building?

- Is water from other properties flowing across the property? In what ways does this affect the building's performance as a library?

- Is the front door easily discernible? Can pedestrian traffic easily reach the front door?

- Are the building footings and foundations solid? (This is determined by reviewing the building walls and floor slabs for any large settlement cracks.)

Take advantage of being able to see these site conditions. Nothing is more embarrassing and harder to live with once your renovation is complete than a problem previously in full view. Don't forget to visit the site during a heavy rain. Look for the direction of the flow of water. Look for ponding of water in parking lots or around the building's perimeter.

\section{Water Problems}

Roof leaks are a fact of life when dealing with renovations or adaptive re-use projects. It seems that most clients forget about servicing a roof until it starts leaking during a rainfall. Even then it takes several rains to convince some that the leak will not heal itself. Once a building is abandoned, one leak often turns into many. Out of sight and out of mind, they cause deterioration of the building. If the damage has not reached the building's structure, however, then the solution is manageable and the renovation must simply include a new roof and maybe some minor roof deck repairs.

A more critical water issue exists, however, if you see signs of water penetrating walls. Look for leaking in lower level floors and basements, or signs of previous leaking such a paint "blooming" on the interior surface of walls (most likely to occur below windows and on walls below the outside grade). Water penetrating the building's walls is almost impossible to stop. Certainly, avoid buildings with multiple signs of through-wall water problems. Be particularly sensitive to through-wall water issues. This problem adversely affects any space occupied by paper, films, archival materials, patrons, or staff. In other words, any library space (except mechanical rooms perhaps) cannot handle problems created by water infiltration. Several approaches to solving this problem include repointing the masonry joints (for masonry veneer and composite masonry buildings), or coating the building with a "waterproofing" wash which consolidates the brick and mortar surfaces. If the renovation or adaptive re-use project is an historical structure, be particularly careful about the choice of these waterproofing materials. Products that allow the walls to "breathe" while creating a waterproof protection are a necessity.

\section{Infrastructure}

Probably one of the major problems pushing libraries into renovation projects is the need to upgrade their utility infrastructure. This is particularly true with the electrical systems. The age of computers, electrically operated devices (i.e., copiers, faxes, scanners, printers, film readers, etc.), increased life safety systems (i.e., fire alarm and fire detections systems) and security systems, and better control of lighting have continued to place more demand on a building's electrical infrastructure. This problem is compounded by a library's need to maintain flexibility for future library space plan adjustments. It is not as simple as continually routing receptacle after receptacle to various locations within the library.

The best solution to dealing with a library's changing electrical infrastructure needs is to develop a separate electrical distribution "system" for power, data, and telephone systems. As an example, floor systems that have been built into the decking supporting the concrete floor have electrical chase ways built in that systematically route raceways through a floor. These chase ways are large enough to house multiple cables and wires to address future growth requirements. They divide a floor into a grid system that allows the wiring to reach (within the scale of the grid) almost any location on the library's floor.

For renovations, this floor raceway system is not an option; however, a very close emulation of it can be developed around under-carpet wiring. Routing of the under-carpet wires from strategically placed junction boxes in new walls can provide a flexible and complete system of wiring options. The supplies for the under-carpet wiring can be routed to these central junction boxes through conduits back to electrical panels, telephone board, or computer rooms, whichever is applicable.

\section{Miscellaneous}

Money and its relationship to renovations: contingency.

A couple of major issues exist which could result in financial calamity after committing to a renovation project. The first 
occurs when the initial project is defined. Be sure that the library program is thoroughly defined and that the design criteria are given to the architect prior to making the initial assessment of any desired building. Nothing will undermine a successful renovation project more than a major change in the program, particularly if the change results in significantly more area or space modifications. Changes are part of a basic construction axiom: "Changes always cost more!".

Unlike a new construction project where more square footage usually can be added to overcome an increase in program space demands, a renovation literally may not be able to respond to the addition of any extra space. This is particularly true if your building is part of a downtown setting where buildings align "main street," side by side. It is also true for sites that are part of an office condominium or mall setting.

Architects are familiar with the fact that a renovation or adaptive re-use project is more susceptible to problems than new construction. Without fail, when walls are demolished or ceilings removed, some "discovery" will be made which requires dollars to fix. If the architect has adequately prepared construction documents that are based on a thorough investigation of the existing structure and infrastructure, these contingents should fall within a ten percent total of the design development budget and five percent of the construction documentation budget.

Also, be prepared to allow adequate time for some schematic design to take place prior to committing to a purchase. Yes, the chance exists that some design fees will be lost if the building fails to lend itself to a library's function; but this early investment may save thousands (or millions) of dollars and much embarrassment later if a purchased building struggles or fails to meet important program requirements. I would suggest that the design investment be monitored closely and proceed in small steps, eliminating more obvious deficiencies early and continuing only as each level of criteria proves acceptable. For example, follow a simple checklist such as the one on this page. Use the list and make certain that each criterion is met before continuing to the next. The earlier items are more important to meet since they could render a potential building undesirable for renovations or adaptive re-use.

\section{Fixture and Furniture Budgets:}

The purpose of a good renovation is to bring an existing facility to "good as new" condition. Don't circumvent success by filling your finished building with old furniture and fixtures. It is amazing how many renovation projects include reuse of existing, worn out furniture that would not even be considered for re-use if the project were new. The standards should be the same. If you would not re-use the furniture in a new facility project, then don't reuse it in your renovation.

\section{ADA Issues:}

ADA issues must be managed in both renovation and new projects. Given the fact that older buildings were built with more confined supporting spaces, small toilets, front entrances accessible only by steps, shallow entry vestibules, narrow hallways, etc., a renovation will face greater challenges in meeting the ADA objectives than new construction. In addition, since a large number of library patrons are older adults, it is important that these challenges be met completely.

Libraries have several advantages over other building types in dealing with handicap-accessible issues. The greatest of these advantages is the fact that on a square-foot basis, a large majority of a library's space is open. Meeting ADA requirements can be as simple as designing appropriate range layouts, aisle clearances, and buying ADA-sensitive furniture. Other advantages include: a preference for a single point of entry, if possible, which means that only one location for building entry ramps may be necessary; and for gang toilets, which tend to minimize premium space needs in toilet areas for ADA compliance.

More challenging design considerations may involve a series of small items such as meeting minimum door widths or having to add an elevator (appropriately sized) in multistory buildings. Given the importance of complying with handicap accessibility needs, I would suggest accepting these as construction-related expenses and proceeding directly toward solution. Doors not wide enough must simply be removed and replaced with wider doors. Include in this correction new leveler-type hardware. The elevator industry has developed construction techniques for drilling shafts for elevators built as retrofits. The only added cost over new is the demolition of a hole in the floor matching the size of the elevator's shaft and perhaps some structural modifications to clear the opening.

\section{Checklist:}

1. Examine a building's total square footage. If the building analysis indicates adequate area to meet program needs (or an addition can be constructed which combines to meet the library's total area needs) then

2. Examine the loading capacities of the building's structure

3. Examine the framing arrangement of a potential building

a. Single story, skeletal framing, slab on grade construction

b. Multistory, steel or concrete frame, interior and exterior skeletal frame

c. Multistory, steel or concrete frame, interior skeletal frame and exterior bearing walls

If the building's structure is adequate or can be made adequate for a reasonable cost, and if the structure allows for a satisfactory flexibility, then

4. Survey for hazardous materials
a. asbestos - friable
b. lead-based paint
c. asbestos - non-friable
d. ground water contaminates

If the building is clear of excessive abatement work

5. Examine the building's life safety system

If stairs are adequate, or can be built to meet remote criteria, then

6. Examine the building's site condition

a. Storm water controlled or reasonably controllable,

b. Room for future growth

c. Building free of major water infiltration in - walls and basement walls

- roof

d. Infrastructure acceptable or correctable

- plumbing

- mechanical

- electrical

7. ADA compliance

8. Miscellaneous items have been considered

9. Money is available to adequately fund the renovation

- contingency dollars of $10 \%$ included

- furniture budget available and adequate

10. Living with construction, prepare a plan 


\section{Construction Obstructions:}

Living with the construction may also present a number of delicate challenges. The key points are to phase construction to allow for reasonable operation of the library and develop construction phases in such a way as to protect patron safety.

Strategies for phasing can include the requirement to complete an addition before any renovations occur to the existing library. If the addition is smaller than the space scheduled to be renovated, then plan your phases in chunks of comparable size or smaller than the addition. These will allow an area to be completely vacant during the construction work. If most of the building is to be renovated, and services cannot be pared down to allow construction to take place in areas totally separate from library use, consider a double move (move out of the existing library during construction and move back in after the construction). Though this approach is extreme, there may be some supporting economics to this arrangement. If the time and effort required to renovate an empty building is significantly shorter and simpler than it would be if the renovation took place around staff and patrons, then this option should be considered. Even if the time and cost are comparable, the added safety and improved operation environment will make the moves worthwhile.

Protection of patrons during the renovations must be of paramount importance. Construction is a dangerous business. In addition, the public is extremely curious and will more than likely migrate toward the renovation operations. The library staff may need to be creative to minimize this tendency. Prepare a construction progress summary for patrons. Arrange with the builders for a safe place (or means) where patrons can see the work occurring (like the hole in a construction fence, designed to allow for viewing a construction site, in lieu of having the curious "climb" the fence for a "view").

During construction, always maintain a reasonable emergency egress system. Consultation with the local building inspector and/or fire marshal will help determine minimum standards. As part of the construction contracts, require that

\begin{tabular}{c}
\hline NCLA Placement Center \\
1997 NCLA Conference, Raleigh, N.C. \\
Please send your available positions or resumes to: \\
James R. Jarrell, chair \\
Placement Center \\
Benjamin Branch Library \\
1530 Benjamin Parkawy \\
Greensboro 27408 \\
Fax:910-33-6781 \\
Hours: Weds., Oct. 8: 10-4; Thurs. Oct. 9: 10-4
\end{tabular}

all existing life safety fire alarm systems, electricity, and telephones remain active during construction except during hours the library is closed. Construction includes the use of torches, cranes, chemicals and other dangerous items; these systems must remain in place to address emergency needs.

\section{Summary:}

A step-by-step analysis is key because as you get further along in your analysis, you will have more and more time and money invested. As you proceed down the checklist, you can take comfort in knowing that the probability of success has increased measurably. Certainly the level of compromise is more acceptable as each step is taken.

Remember that architecture is the business of compromise. Don't sacrifice function, but recognize that compromises may occur more frequently during a renovation project than a new project. It is important to spend some dollars to gain as much building flexibility as possible. Flexibility is a necessary component in library design and, if the right building is found, it is an attainable goal even in a renovation project.

One last consideration should be made. During the selection of an architect, give ample consideration to architects with library experience, but also consider that the skills relating to renovations and adaptive re-use of buildings are equally important. In fact, it may be more practical to "educate" your architect about library needs than to break in an architect to the practice of renovations or adaptive re-use. After all, you do have your own library knowledge to work with in educating an architect about planning a library. At a minimum, be sure that the architect has no bias toward designing new facilities.

With the right review and planning, a successful and cost effective renovation or adaptive re-use library project can be managed. If, during the construction process, it appears that the project is overwhelming, take comfort in knowing that it will be over soon and that the next project will probably be twenty years away. And lastly, remember, new projects also are overwhelming at times.

\section{References}

${ }^{1}$ Bette-Lee Fox and Corinne O. Nelson, "Renovations and Additions - On the Rise," Library Journal 119 (December 1994): 41-52.

2 R. S. Means. Square Foot Costs, 18th Annual Edition, 1995.

3 North Carolina Building Code, Volume 1. (General Construction), 1996 ed. (adapted from 1994 Standard Building Code).

${ }^{4}$ Requirements of North Carolina's NESHAP program.

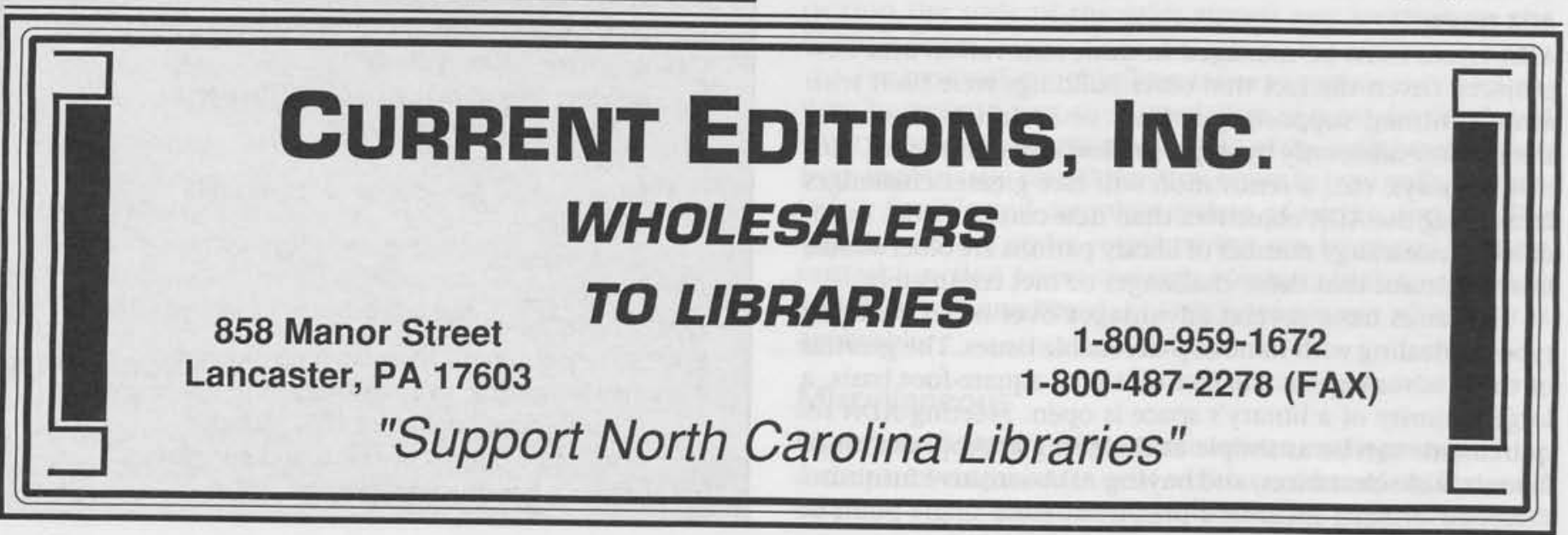

